\title{
Implications of the 21-gene recurrence score assay (Oncotype DX) on adjuvant treatment decisions in ER-positive early- stage breast cancer patients: experience of Kuwait Cancer Control Center
}

\author{
Salah Fayaz ${ }^{1}$, Heba El-Sayed Eissa ${ }^{1,2}$ and Gerges Attia Demian ${ }^{1,2^{*}}$ (D)
}

\begin{abstract}
Background: The Oncotype DX is a quantitative assay of the expression of 16 tumor-related genes and 5 reference genes that predicts the potential of adjuvant chemotherapy benefit in estrogen receptor (ER)-positive early breast cancer patients. The study aims to evaluate the impact of Oncotype DX as a tool for adjuvant treatment decision of ER-positive, HER2-negative, NO/N1 early-stage breast cancer patients and to determine which clinicopathological criteria derived the greatest advantage.

Results: A hundred patients at a median age of 50 years were included. TNM stage distribution was 34, 63, and 3 patients for stages I, II, and IIIA respectively. Fifty-four patients had luminal A and 46 had luminal B tumors. The recurrence score (RS) results were low, intermediate, and high risk in 54, 34, and 12 patients respectively. Before the test results, adjuvant chemoendocrine therapy (CET) was recommended for 46 patients while 54 were advised for endocrine therapy (ET). After getting the test results, 25 patients received CET (1, 12, and12 patients in the low-, intermediate-, and high-risk groups respectively) and 75 received ET. Treatment change was documented in 37 patients (8 patients from ET to CET and 29 from CET to ET; $p=0.001$, McNemar test). Treatment change was significant among patients $\leq 50$ years, luminal B tumors, stage II and IIIA disease, and node-positive disease.

Conclusion: Oncotype DX testing resulted in significant changes in the adjuvant treatment decisions in ER-positive, HER2-negative early breast cancer particularly in the case of young, luminal B, N1, and stage II-IIIA disease.
\end{abstract}

Keywords: Early breast cancer, Adjuvant systemic treatment, Oncotype DX recurrence score

\section{Background}

The clinicopathologic features have traditionally guided the decision-making of chemotherapy use in the adjuvant sitting of early breast cancer [1]. The most effective chemotherapy regimens offer an average of one third reduction in 10-year breast cancer mortality and 30\% relative reduction in the risk of recurrence [2]. Among estrogen receptor-positive (ER-positive), axillary nodenegative (N0) patients, this would result in an absolute gain of 5\%. Many of these patients would be overtreated

\footnotetext{
* Correspondence: gergesattia@yahoo.com

'Department of Radiation Oncology, Kuwait Cancer Control Center, Kuwait

${ }^{2}$ National Cancer Institute, Cairo University, Egypt
}

if chemotherapy is given on the basis of clinicopathologic features alone and would have been adequately managed with endocrine therapy alone. The recent advances in gene expression profiling of breast tumors have improved the ability to predict a patient's risk of distant recurrences and likelihood of response to endocrine therapy and/or chemotherapy. The 21-gene recurrence score (RS) assay stratifies ER-positive, HER2negative patients according to the risk for distant recurrence into low-, intermediate-, and high-risk categories, independent of their clinicopathologic features [3], and predicts the benefit of adjuvant chemotherapy $[4,5]$. 


\section{Aim of the work}

The study was conducted to evaluate the impact of Oncotype DX recurrence score on adjuvant treatment decision of ER-positive, early-stage breast cancer patients to gain insight into the real-world utility of the assay in Kuwait and to determine which clinicopathological criteria derived the greatest advantage.

\section{Methods}

A total of 100 Oncotype DX recurrence score (RS) results were available to our center for ER-positive, HER2negative, N0/N1 excised invasive breast tumors. The RS were requested on the excised tumor tissues during the period between January 2011 and October 2017. Recruitment of patients for the test was slow in the first 4 years (14 patients) as patients were required to pay out-ofpocket the test cost. However, between 2015 and 2017, more patients (86 patients) had the test as it came to be sponsored by the Ministry of Health.

The decisions to go for Oncotype DX test is made by the multidisciplinary team (MDT) upon having the surgical pathology final report including tumor type, size, grade, estrogen and progesterone receptors (ER and PR), HER2, and nodal status. According to our National Guidelines (https://kuwaitcancercenter.net/Physicians/ Guidelines.html), the option of either endocrine therapy (ET) or chemoendocrine (CET) adjuvant treatment is discussed with the patient before the RS test result and the decision is documented taking into account both the patient and oncologist point of view. Once RS is made available, a second meeting is held and final decision is made and recorded taking into consideration the information added by test score.

\section{Statistical analysis}

The primary objective of the study is to assess the proportion of change in the treatment recommendations before and after RS results. The McNemar test is used to assess the association of recurrence score results with the changes in the treatment decisions.

\section{Results}

The clinicopathological characteristics of the studied women are summarized in Table 1 . The median age is 50 years (range 38-74). The majority (94\%) had ductal histology. The tumor was resected in $78 \%$ by wide excision and in $22 \%$ by mastectomy. Axillary sentinel lymph node (SLN) biopsy was the form of axillary staging in $84 \%$ and axillary clearance in $16 \%$. Median tumor size was $2.2 \mathrm{~cm}$ (range $0.7-7 \mathrm{~cm}$ ). Seventy-six percent were node negative (N0), $10 \%$ showed microscopic metastasis (N1mic), and $14 \%$ had positive lymph nodes (N1). Median number of positive nodes was 1 (range $1-3$ ). TNM stage distribution was $34 \%, 63 \%$, and $3 \%$ for stages I, II, and III respectively.

RS results were low, intermediate, and high risk in 54, 34 , and 12 patients respectively. Before the test results, the multidisciplinary team recommended adjuvant CET in 46 patients and ET alone in 54 patients based on the clinicopathological criteria (Table 2). After getting the test results, 25 patients received CET $(1,12$, and12 patients in the low-, intermediate-, and high-risk groups respectively) and 75 received ET. Treatment was changed in 37 patients (37\%) after RS was made available ( $p$ $=0.001$, McNemar test). In 29 of the 46 patients (63\%) who were recommended CET, treatment was revised to ET alone, and in 8 of the 54 (14.8\%), adjuvant therapy was changed from ET to CET. The overall reduction in chemotherapy recommendation was met in 21 women (21\%). Among the 54 patients proved to be low risk (RS $<18$ ), 18 were initially recommended chemotherapy (of whom only one received CET) and 36 were recommended endocrine treatment (none received chemotherapy). For the 34 intermediate-risk ( $R S \geq 18$ and <30) women, 17 were recommended CET (of them 5 received) and $17 \mathrm{ET}$ alone (7 received CET). Among 12 high risk $(\geq 31)$ patients, 11 were initially advised for CET and only 1 was advised for ET alone (all received chemotherapy).

Treatment change was significant among patients $\leq 50$ years, luminal B tumors, stage II and IIIA disease, and node-positive disease (Table 3 ).

The definition of the RS risks group was re-defined in concordance with the recently published TailorX study [6], into two groups (low or high) with a cutoff modulated by clinicopathological risk for the patients $\leq 50$ years. Patients aged $>50$ years with $\mathrm{RS} \leq 25$ and $\leq$ 50 years with $\mathrm{RS}<16$ are considered for ET while those patients $<50$ years with $\mathrm{RS} \geq 16$ and $>50$ years with RS $>25$ are considered for CET. As the TailorX study included only axillary node-negative patients, the reanalysis included the 76 node-negative patients. Should the results be available, the treatment would have been changed in 18 patients (24\%): from CET to ET in 9 and from ET to CET in 9.

The median follow-up was 12 months (3-75 months). One patient among the low risk group had a systemic relapse in the bone after 30 months of adjuvant tamoxifen. Another developed contralateral breast cancer after 2 years of adjuvant letrozole, likely a second primary cancer.

\section{Discussion}

In the era of personalized medicine, the "one size fits all" model is no longer attractive. The Oncotype DX assay which is a quantitative analysis of gene expression assessing the expression of 16 tumor-related genes and 5 
Table 1 Patients, tumor, and treatment characteristics of 100 patients who had Oncotype DX recurrence score assessment

\begin{tabular}{|c|c|c|c|c|c|c|c|c|c|}
\hline & & & $\operatorname{Rec}$ & ice sco & k cate & & & & $p$ \\
\hline & Who & & Low & & Inte & risk & $\mathrm{High}$ & & \\
\hline & $n$ & $\%$ & $n$ & $\%$ & $n$ & $\%$ & $n$ & $\%$ & \\
\hline All patients & 100 & 100 & 54 & 54 & 34 & 34 & 12 & 12 & \\
\hline Age & & & & & & & & & \\
\hline Age $\leq 50$ years & 51 & 51 & 30 & 55.6 & 16 & 47.1 & 5 & 41.7 & 0.583 \\
\hline Age $>50$ years & 49 & 49 & 24 & 44.4 & 18 & 52.9 & 7 & 58.3 & \\
\hline Menopausal status & & & & & & & & & \\
\hline Premenopausal & 59 & 59 & 35 & 64.8 & 19 & 55.9 & 5 & 41.7 & 0.304 \\
\hline Postmenopausal & 41 & 41 & 19 & 35.2 & 15 & 44.1 & 7 & 58.3 & \\
\hline Tumor histological g & & & & & & & & & \\
\hline Grade 1 & 15 & 15 & 11 & 20.4 & 4 & 11.8 & 0 & 0 & 0.003 \\
\hline Grade 2 & 64 & 64 & 32 & 59.3 & 27 & 79.4 & 5 & 41.7 & \\
\hline Grade 3 & 17 & 17 & 9 & 16.7 & 2 & 5.9 & 6 & 50 & \\
\hline Grade (unknown) & 4 & 4 & 2 & 3.7 & 1 & 2.9 & 1 & 8.3 & \\
\hline Ki-67 index & & & & & & & & & \\
\hline Ki-67 $\leq 15$ & 51 & 51 & 37 & 68.5 & 13 & 38.2 & 1 & 8.3 & $<0.001$ \\
\hline $\mathrm{Ki}-67>15$ & 38 & 38 & 11 & 20.4 & 17 & 50 & 10 & 83.3 & \\
\hline Ki-67 (unknown) & 11 & 11 & 6 & 11.1 & 4 & 11.8 & 1 & 8.3 & \\
\hline Tumor type & & & & & & & & & \\
\hline IDC & 94 & 94 & 52 & 96.3 & 30 & 88.2 & 12 & 100 & 0.195 \\
\hline ILC & 6 & 6 & 2 & 3.7 & 4 & 11.8 & 0 & 0 & \\
\hline Primary tumor surgic & & & & & & & & & \\
\hline WLE & 78 & 78 & 39 & 72.2 & 29 & 85.3 & 10 & 83.3 & .316 \\
\hline Mastectomy & 22 & 22 & 15 & 27.8 & 5 & 14.7 & 2 & 16.7 & \\
\hline Axillary surgical man & & & & & & & & & \\
\hline SLN & 84 & 84 & 46 & 85.2 & 28 & 82.4 & 10 & 83.3 & 0.938 \\
\hline Axillary clearance & 16 & 16 & 8 & 14.8 & 6 & 17.6 & 2 & 16.7 & \\
\hline pT stage & & & & & & & & & \\
\hline pT1 & 39 & 39 & 24 & 44.4 & 13 & 38.2 & 2 & 16.7 & 0.381 \\
\hline pT2 & 55 & 55 & 26 & 48.1 & 20 & 58.8 & 9 & 75 & \\
\hline pT3 & 6 & 6 & 4 & 7.4 & 1 & 2.9 & 1 & 8.3 & \\
\hline
\end{tabular}

pN stage

$\begin{array}{lllllllll}\text { pN0 } & 76 & 76 & 42 & 77.8 & 25 & 73.5 & 9 & 75 \\ \text { pN1mic } & 10 & 10 & 5 & 9.3 & 4 & 11.8 & 1 & 8.3 \\ \text { pN1 } & 14 & 14 & 7 & 13 & 5 & 14.7 & 2 & 16.7\end{array}$

UICC-AJCC TNM stage

$\begin{array}{lllllllll}\text { la } & 31 & 31 & 18 & 33.3 & 11 & 32.4 & 2 & 16.7 \\ \text { Ib } & 3 & 3 & 3 & 5.6 & 0 & 0 & 0 & 0 \\ \text { Ila } & 47 & 47 & 24 & 44.4 & 16 & 47.1 & 7 & 58.3 \\ \text { Ilb } & 16 & 16 & 8 & 14.8 & 6 & 17.6 & 2 & 16.7 \\ \text { IIla } & 3 & 3 & 1 & 1.9 & 1 & 2.9 & 1 & 8.3\end{array}$

Lymphovascular invasion

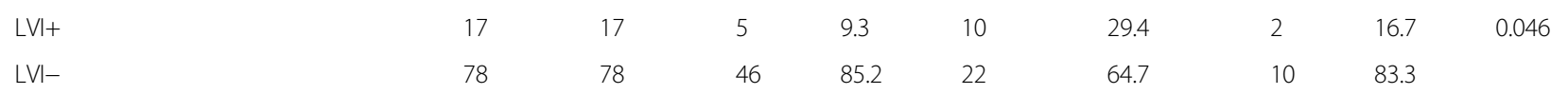


Table 1 Patients, tumor, and treatment characteristics of 100 patients who had Oncotype DX recurrence score assessment (Continued)

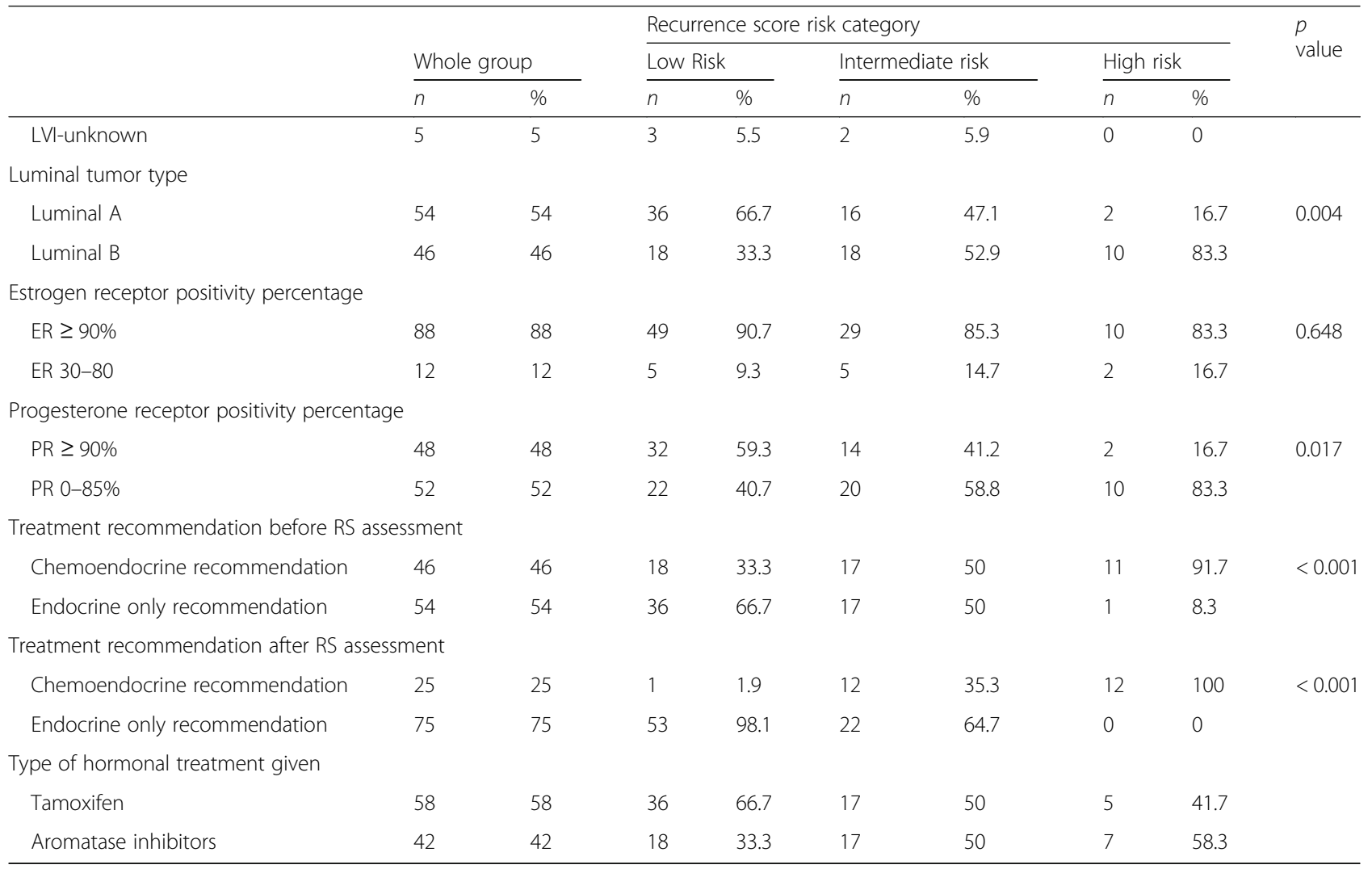

IDC invasive duct carcinoma, ILC invasive lobular carcinoma, WLE wide local excision, SLN sentinel lymph node

reference genes is an excellent example of the personalized medicine. It is not merely a prognostic tool but more importantly predicts the potential of chemotherapy responsiveness. In the prospective confirmatory trial involving 10,253 women with HR-positive, HER2-negative, axillary node-negative breast cancer, 1626 women (15.9\%) who had a recurrence score of 0 to 10 were assigned for endocrine therapy alone. The 5-year distant recurrence-free survival was $99.3 \%$, and the overall survival was $98.0 \%$ [7]. Also, among 6711 women with a recurrence score of 11 to 25 who were randomized to receive either ET or CET, ET proved to be noninferior regarding invasive disease-free survival at 9 years $(83.3 \%$ for ET vs. $84.3 \%$ for CET), distant recurrence-free survival $(94.5 \%$ vs. $95.0 \%)$, and overall survival $(93.9 \%$ vs. 93.8\%). Some benefit of chemotherapy was seen in women $\leq 50$ years of age having a recurrence score of 16 to 25 (TailorX study) [6].

In the present study, Oncotype DX assay has significantly impacted the prescription of chemotherapy. Of 46 patients recommended for CET therapy, 29 (63\%) changed to ET alone sparing a group of patients the toxicity as well as the economic impact of chemotherapy. Even more importantly, 8 out of 54 patients $(14.8 \%)$ of patients who were advised for ET were prescribed CET therapy following Oncotype DX testing. These patients are the most likely to get benefit from the test as they offered a treatment which might significantly reduce their risk of relapse.

The overall change of treatment recommendations was documented in $37 \%$ of our N0/N1 patients. The UK figure was 27\% [8]; Germany, 33\% [9]; Spain, 32\% [10]; and France, 34\% [11]. The treatment change was 32\% in a pooled meta-analysis of the previous European studies. In Ontario, Canada, the percentage was 38\% [12]; Mexico, 32\% [13]; Japan, 38\% [14]; Hong Kong, 23.3\% [15]; and United Arab Emirates, 27.7\% [16].

The variation of change in treatment recommendation is likely related to the proportion of patients who had a pre-test CET recommendation which is a sequence of the clinicopathological risk factors like age, menopausal status, tumor grade, lymph node status, and Ki-67 proliferative index. In the Japanese study as well as this study, $\mathrm{N} 1$ patients were included thus boosting the initial CET advise. In node-positive patients, a rate of treatment change of 51\% was reported in 138 retrospectively studied patients [17].

In this study, a strong association was shown between RS and clinicopathological factors like tumor grade, Ki67 index, and luminal tumor type. No grade I tumors 
Table 2 Clinicopathological characteristics of patients according to their initially suggested treatment

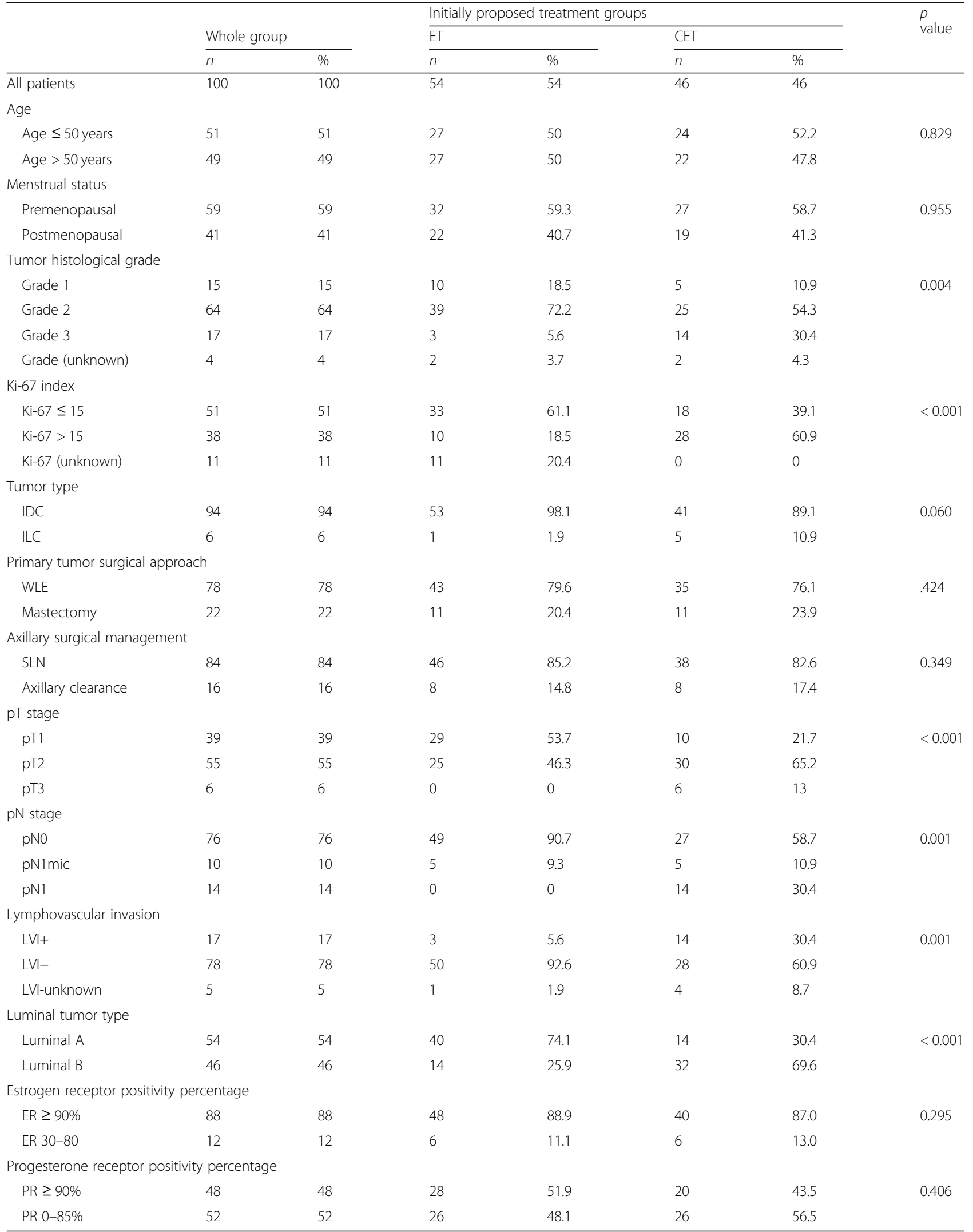


Table 3 Summary of the treatment change among different subgroups of the 100 patients who had Oncotype DX recurrence score assessment

\begin{tabular}{|c|c|c|c|c|c|c|}
\hline & & \multicolumn{4}{|c|}{ Treatment given } & \multirow{3}{*}{$\begin{array}{l}\text { Exact } \\
\text { sig. }\end{array}$} \\
\hline & & \multicolumn{2}{|c|}{ Endocrine } & \multicolumn{2}{|c|}{ Chemoendocrine } & \\
\hline & & $\bar{n}$ & $\%$ & $\bar{N}$ & $\%$ & \\
\hline \multirow{27}{*}{$\begin{array}{l}\text { Treatment Recommendation } \\
\text { before RS }\end{array}$} & Whole group & & & & & \\
\hline & Endocrine & 46 & 46 & 8 & 8 & 0.001 \\
\hline & Chemoendocrine & 29 & 29 & 17 & 17 & \\
\hline & Luminal A & & & & & \\
\hline & Endocrine & 32 & 59.3 & 8 & 14.7 & 0.648 \\
\hline & Chemoendocrine & 11 & 29.4 & 3 & 5.6 & \\
\hline & Luminal B & & & & & \\
\hline & Endocrine & 14 & 30.4 & 0 & 0 & $<0.001$ \\
\hline & Chemoendocrine & 18 & 39.2 & 14 & 30.4 & \\
\hline & $\leq 50$ years & & & & & \\
\hline & Endocrine & 25 & 49.1 & 2 & 3.9 & 0.002 \\
\hline & Chemoendocrine & 15 & 29.4 & 9 & 17.6 & \\
\hline & $>50$ years & & & & & \\
\hline & Endocrine & 21 & 41.9 & 6 & 12.2 & 0.115 \\
\hline & Chemoendocrine & 14 & 28.6 & 8 & 16.3 & \\
\hline & NO & & & & & \\
\hline & Endocrine & 42 & 55.2 & 7 & 9.2 & 0.093 \\
\hline & Chemoendocrine & 16 & 21.1 & 11 & 14.5 & \\
\hline & $\mathrm{N} 1$ & & & & & \\
\hline & Endocrine & 4 & 16.7 & 1 & 4.2 & 0.002 \\
\hline & Chemoendocrine & 13 & 54.1 & 6 & 25 & \\
\hline & Stage I & & & & & \\
\hline & Endocrine & 24 & & 5 & & 1.0 \\
\hline & Chemoendocrine & 4 & & 1 & & \\
\hline & Stages II and III & & & & & \\
\hline & Endocrine & 22 & & 3 & & $<0.001$ \\
\hline & Chemoendocrine & 25 & & 16 & & \\
\hline
\end{tabular}

had a high RS. Similarly, in a study from Ontario, no high RS tumors were grade I in 1000 analyzed patients. These data suggest that such factors might serve as a tool to select patients for whom the expensive RS test can be skipped. For instance, if the clinicopathological factors predicted a low probability for high RS (which is the sole factor to consider chemotherapy), Oncotype DX might be withdrawn. Furthermore, treatment changes were more significant among younger, $\mathrm{N} 1$, luminal $\mathrm{B}$, and more than stage 1 disease in whom the change is more likely from CET to ET; thus, patients can be prioritized in case of financial restrictions.

\section{Conclusion}

In conclusion, the use of the Oncotype DX assay led to significant changes in the adjuvant treatment decisions in ER-positive, HER2-negative, early breast cancer. Ultimately, the test resulted in a net reduction in treatment recommendations for adjuvant chemotherapy particularly in young patients, luminal B tumors, N1 disease, and stage II to IIIA disease.

\section{Abbreviations}

CET: Chemoendocrine therapy; ER: Estrogen receptor; ET: Endocrine therapy; Her 2: Human epidermal growth factor receptor 2; NO: Lymph node negative; N1mic: Microscopic metastasis in lymph nodes; RS: Recurrence score

Acknowledgements

Not applicable

Authors' contributions

SF has contributed in the study conception, design of the work, data interpretation, revision of the work, and final approval of the version. HE has contributed in the data acquisition and interpretation, revision of the work, 
and final approval of the version for publication. GD has contributed in the study design, data analysis and interpretation, drafting of the work, and final approval of the manuscript. All authors have read and approved the manuscript and are accountable for all aspects of the work.

\section{Funding}

Not applicable.

\section{Availability of data and materials}

The datasets used and analyzed during the current study are available from the corresponding author on reasonable request.

\section{Ethics approval and consent to participate}

The research was approved by the scientific committee, Kuwait Cancer Control Center, both scientifically and ethically. Being a retrospective study, there was no consent for patients' participation required in the study.

\section{Consent for publication}

Not applicable.

\section{Competing interests}

The authors declare that they have no competing interests.

Received: 24 September 2019 Accepted: 13 February 2020 Published online: 04 March 2020

\section{References}

1. Harris LN, Ismaila N, McShane LM, Andre F, Collyar DE, Gonzalez-Angulo AM, et al. Use of biomarkers to guide decisions on adjuvant systemic therapy for women with early stage invasive breast cancer: American Society of Clinical Oncology clinical practice guideline. J Clin Oncol. 2016;34:1134-50.

2. Peto R, Davies C, Godwin J, Gray R, Pan HC, Clarke M, et al. Comparisons between different polychemotherapy regimens for early breast cancer: meta-analyses of long-term outcome among 100,000 women in 123 randomised trials. Lancet. 2012;379:432-44.

3. Paik S, Shak S, Tang G, Kim C, Baker J, Cronin M, et al. Multigene assay to predict recurrence of tamoxifen-treated, node-negative breast cancer. $\mathrm{N}$ Engl J Med. 2004;351(27):2817-26.

4. Paik S, Tang G, Shak S, Kim C, Baker J, Kim W, et al. Gene expression and benefit of chemotherapy in women with node-negative, estrogen receptorpositive breast cancer. J Clin Oncol. 2006;24(23):3726-34.

5. Albain KS, Barlow WE, Shak S, Hortobagyi GN, Livingston RB, Yeh IT, et al. Prognostic and predictive value of the 21 -gene recurrence score assay in postmenopausal women with node-positive, estrogen- receptor-positive breast cancer on chemotherapy: a retrospective analysis of a randomised trial. Lancet Oncol. 2010;11(1):55-65.

6. Sparano JA, Gray RJ, Makower DF, Pritchard Kl, Albain KS, Hayes DF, et al Adjuvant chemotherapy guided by a 21-gene expression assay in breast cancer. N Engl J Med. 2018;379(2):111-21.

7. Sparano JA, Gray RJ, Makower DF, Pritchard Kl, Albain KS, Hayes DF, et al Prospective validation of a 21-gene expression assay in breast cancer. N Engl J Med. 2015;373(21):2005-14.

8. Holt S, Bertelli G, Humphreys I, Valentine W, Durrani S, Pudney D, et al. A decision impact, decision conflict and economic assessment of routine Oncotype DX testing of 146 women with node-negative or pNImi, ERpositive breast cancer in the UK. Br J Cancer. 2013;108(11):2250-8.

9. Eiermann W, Rezai M, Kümmel S, Kühn T, Warm M, Friedrichs $K$, et al. The 21-gene recurrence score assay impacts adjuvant therapy recommendations for ER-positive, node-negative and node-positive early breast cancer resulting in a risk-adapted change in chemotherapy use. Ann Oncol. 2013; 24(3):618-24.

10. Albanell J, González A, Ruiz-Borrego M, Alba E, García-Saenz JA, Corominas $J M$, et al. Prospective transGEICAM study of the impact of the 21-gene recurrence score assay and traditional clinicopathological factors on adjuvant clinical decision making in women with estrogen receptor-positive (ER+) node-negative breast cancer. Ann Oncol. 2012;23(3):625-31.

11. Gligorov J, Pivot XB, Jacot W, Naman HL, Spaeth D, Misset JL, et al. Prospective clinical utility study of the use of the 21-gene assay in adjuvant clinical decision making in women with estrogen receptor-positive early invasive breast cancer: results from the SWITCH Study. Oncologist. 2015; 20(8):873-9.
12. Levine MN, Julian JA, Bedard PL, Eisen A, Trudeau ME, Higgins B, et al. Prospective evaluation of the 21-gene recurrence score assay for breast cancer decision-making in Ontario. J Clin Oncol. 2016;34(10):1065-71.

13. Bargallo JE, Lara F, Shaw-Dulin R, Perez-Sánchez V, Villarreal-Garza C, Maldonado-Martinez $\mathrm{H}$, et al. A study of the impact of the 21-gene breast cancer assay on the use of adjuvant chemotherapy in women with breast cancer in a Mexican public hospital. J Surg Oncol. 2015;111(2):203-7.

14. Yamauchi H, Nakagawa C, Takei H, Chao C, Yoshizawa C, Yagata H, et al. Prospective study of the effect of the 21-gene assay on adjuvant clinical decision-making in Japanese women with estrogen receptor positive, nodenegative, and node-positive breast cancer. Clin Breast Cancer. 2014;14(3): $191-7$.

15. Leung RC, Yau TC, Chan MC, Chan SW, Chan TW, Tsang YY, et al. The impact of the Oncotype DX breast cancer assay on treatment decisions for women with estrogen receptor-positive, node-negative breast carcinoma in Hong Kong. Clin Breast Cancer. 2016;16(5):372-8.

16. Jaafar H, Bashir MA, Taher A, Qawasmeh K, Jaloudi M. Impact of Oncotype DX testing on adjuvant treatment decisions in patients with early breast cancer: a single-center study in the United Arab Emirates. Asia Pac J Clin Oncol. 2014;10(4):354-60.

17. Oratz R, Kim B, Chao C, Skrzypczak S, Ory C, Bugarini R, et al. Physician survey of the effect of the 21-gene recurrence score assay results on treatment recommendations for patients with lymph node-positive, estrogen receptor-positive breast cancer. J Oncol Pract. 2011;7(2):94-9.

\section{Publisher's Note}

Springer Nature remains neutral with regard to jurisdictional claims in published maps and institutional affiliations.

\section{Submit your manuscript to a SpringerOpen ${ }^{\circ}$ journal and benefit from:}

- Convenient online submission

- Rigorous peer review

- Open access: articles freely available online

High visibility within the field

- Retaining the copyright to your article

Submit your next manuscript at $\boldsymbol{\sim}$ springeropen.com 